\title{
Factors contributing to non-compliance to routine ante-natal haematinics among pregnant women attending ante-natal clinic in University of Maiduguri Teaching Hospital, Borno, Nigeria
}

\author{
Idris Umar Hambali ${ }^{1 *}$, Quraibah Gado Kodomi ${ }^{2}$, Lola Nelson ${ }^{2}$, Sarah Dika Martins ${ }^{2}$, \\ Memunat Umar Hambali ${ }^{3}$, Ya-kime Gado Kodomi ${ }^{4}$, Maryam Karagama ${ }^{4}$
}

\begin{abstract}
${ }^{1}$ Department of Preventive Medicine and Public Health, Faculty of Veterinary Medicine, University of Maiduguri, PMB 1069, Borno, Nigeria

${ }^{2}$ Department of Nursing Science, College of Medical Sciences, University of Maiduguri, PMB 1069, Borno, Nigeria ${ }^{3}$ Department of Curriculum and Instruction, Faculty of Education, Kashim Ibrahim College of Education, Maiduguri, Borno, Nigeria

${ }^{4}$ Department of Maternity Ward, Ali Mamman Shuwa Hospital, Maiduguri, Borno, Nigeria
\end{abstract}

Received: 23 August 2016

Revised: 25 September 2016

Accepted: 26 September 2016

\author{
*Correspondence: \\ Dr. Idris Umar Hambali, \\ E-mail: idrisumarhambali@yahoo.com
}

Copyright: () the author(s), publisher and licensee Medip Academy. This is an open-access article distributed under the terms of the Creative Commons Attribution Non-Commercial License, which permits unrestricted non-commercial use, distribution, and reproduction in any medium, provided the original work is properly cited.

\section{ABSTRACT}

Background: This study was carried out on factors contributing to non-compliance to routine ante-natal haematinics among pregnant women attending ante-natal clinic in University of Maiduguri Teaching Hospital. Descriptive research design in which Yaro Yamen's formular was used to calculate the sample size of 130. The objectives of the study were: to identify types of haematinics and duration of intake during ante natal care, to determine the factors contributing to non-compliance of haematinics and to determine the attitude of pregnant women toward haematinic use.

Methods: Data was collected using a self-developed questionnaire and presented in frequency distribution tables and histogram.

Results: The result showed that the response of the age variation of the respondents at 21-30 years old had the maximum age participation in haematinics with $62 \%$ of response, responses based on the choice of haematinics $50 \%$ went for folic acid, trimester intake of haematinics among pregnant women about $48 \%$ accepted that they made use of it during pregnancy period, the result also revealed that pregnant women take haematinics once a day with $63 \%$ respondents, pregnant women with higher educational qualification made more use of haematinics with $70 \%$ responses and that non-compliance to haematinics intake based on cultural believe contributed few to the use of haematinics with $36 \%$ while $64 \%$ of the respondents accepted cultural believe was not the factor contributing to noncompliance of haematinics usage.

Conclusions: In conclusion, this study provided information on the general response to factors contributing to noncompliance to routine ante natal haematinics among pregnant women attending ante natal clinic in UMTH which was about $62 \%$. It is therefore recommended that the government should put in place relevant agencies to pro-actively inform pregnant women cut across all age groups, level of education, occupational classes, culture inclinations and financial status on the medical importance of haematinics intake during the gestation period.

Keywords: Ante-natal clinic, Haematinics, Non-compliance, Pregnant women, UMTH 


\section{INTRODUCTION}

Haematinics are chemical agents that improve the quality of blood, increase haemoglobin level and the number of erythrocytes. They include; Iron (Fe), Folic acid, Vitamin B12, Zinc (Zn) and Cobalt (Co). Haematinics (particularly Iron) lead to the rise in serum erythropoietin which decreases during pregnancy. Deficiency of these essential haematinics arising from increased requirements and inadequate intake may have far reaching effects on both mother and the foetus. Iron which is the main component of haemoglobin, its deficiency is the most common cause of anaemia in pregnancy. ${ }^{1}$ Folic acid reduces the risk of birth defects in foetus although the mechanism is not known, complications such as folic acid anaemia, spinabifida, anencephaly and encephalocele occur when it is deficient during pregnancy. Vitamin B12 is a cyanocobalamin, plays a role in the synthesis of Deoxyribonucleic acid, Ribonucleic acid and hypoproteins by acting as a cofactor for enzymes. ${ }^{2}$ Mary and Terry, 2003, reported that Haematinic deficiency in pregnancy will result in an increased erythropoietic drive on the bone marrow and if all women do not receive haematinic supplemental ion throughout pregnancy then this must be assessed and supplementation provided as required. The physiological anaemia which accompanies pregnancy is often exacerbated by deficiencies of iron or folic acid. When the diet of pregnant women is supplemented by these two haematinics the increase in red cell mass is doubled. ${ }^{3}$

The practice of haematinic supplementation during pregnancy is widespread despite the fact that it is recommended only when iron deficiency is documented. ${ }^{4}$ A recent study has cast considerable doubt on the assumption that it is appropriate to treat all pregnant women with iron and folic acid supplements, it also showed that the best feotal outcomes as indicated by small proportions of low birthweight infants and of preterm infants were achieved when haemoglobin $(\mathrm{Hb})$ levels fell to $<10.5 \mathrm{~g} / \mathrm{dl}$ at some stage during gestation. ${ }^{5}$ Haematinic supplementation increases haemoglobin concentration, which reduces the putative effects of lower blood viscosity to the fetus. However iron deficiency is common in pregnancy, even in relatively affluent populations. Iron deficiency has an adverse effect on the ratio of placental weight to birthweight, which may lead to increased incidence of hypertension in later life. ${ }^{6}$ Erythropoiesis is regulated by erythropoietin (EPO), a glycoprotein hormone produced mainly in the kidney of the adult and liver of the fetus in response to hypoxia, EPO does not cross the placenta, so maternal serum levels are not affected by foetal production of the hormone. Three observations made by Malek and Sager, suggest that EPO is an important determinant in the control of erythropoiesis during pregnancy. ${ }^{7}$ Firstly the EPO concentration increases throughout pregnancy, and by term is approximately double the level at booking. Secondly, at least in cell lines, EPO has been shown to regulate iron metabolism. Thirdly, prophylaxis with iron and folic acid blunts the serum EPO response, particularly in the third trimester.

Pregnancy complications indicate that women with severe anaemia have an increased risk of developing complications, particularly during and after birth. They may also develop postnatal depression (which some parents experience after having a baby). Studies suggests babies born to mothers who have untreated anaemia are more likely to be born prematurely (before the 37th week of pregnancy), have a low birth weight, have problems with iron levels themselves, do less well in mental ability tests, increased risk of infection, heart and lungs problems, restless leg syndrome. ${ }^{8}$ Non-compliance to haematinic drugs among pregnant women is the major cause of anaemia during pregnancy especially in many developing countries in Africa, which is one of the major causes of maternal mortality in Nigeria. ${ }^{4}$ The major factors that contribute to non-compliance are the duration of the drug intake which is usually for months. In the Northern part of the country, cultural believe plays an important role in pregnant women's decision to seek health care and to comply with a prescribed treatment regime, little have been done locally to establish home based data on compliance with haematinics in combating anaemia. It is recommended that all women who are pregnant take haematinics i.e. ferrous lactate $100 \mathrm{mg}$, folic acid $5 \mathrm{mg}$ daily throughout pregnancy as a prophylactic measure. This has been shown to minimize incidence of babies born with neural tubes defect and also prevent anaemia. ${ }^{9}$

Anaemia in pregnancy continues to be a major health problem in most developing countries, with significant adverse effects for both mother and infant. ${ }^{10}$ Iron deficiency is the main underlying cause for anaemia in pregnancy followed by folate deficiency. Anaemia has previously been shown to be associated with adverse pregnancy outcomes. What has not been clearly demonstrated is the effect of treatment of anaemia in pregnancy with haematinics on pregnancy outcome. ${ }^{11}$ According to the most recent and available national data now more than two decades old the prevalence of anemia among pregnant women in Nigeria is 67 percent, making it a severe public health problem as defined by WHO standards . Though the prevalence of anemia is equally high among non-pregnant women of reproductive age (62 percent), pregnancy is associated with a two-fold increased risk of anemia. Regionally, the highest rates of maternal anemia are found in the South-West zone. In a more recent study among pregnant women seeking antenatal care at a medical center in Nigeria's southwestern Oyo State, anemia prevalence was found to be 58 percent. $^{12}$ Additionally, low socioeconomic status was significantly associated with higher prevalence rates and increased severity of anemia. Anaemia in pregnancy continues to be a common problem in many developing countries where poverty, ignorance and disease are still prevalent among the people. Worldwide, it is estimated that 58.27 million women are anaemic during pregnancy, 
of whom 55.75 million $(95.7 \%)$ live in developing countries.

A recent estimation suggest that up to $60 \%$ of pregnant women in developing countries including Nigeria may be Folic acid anaemic, and nearly $7 \%$ of pregnant women are severely anaemic Anaemia is reported to be significantly associated with maternal mortality in developing countries, where it is directly or indirectly responsible for $20-30 \%$ of all maternal deaths. ${ }^{13}$ According to WHO the mean minimum acceptable haemoglobin level during pregnancy by criteria is taken to be $11 \mathrm{~g} / \mathrm{dL}$ (PCV of 33\%) in the first half of pregnancy and $10.5 \mathrm{~g} / \mathrm{dL}$ in the second half of pregnancy. The World Health Organization further divide anaemia in pregnancy into: mild anaemia (haemoglobin $10-10.9 \mathrm{~g} / \mathrm{dL}$ ), moderate anaemia ( $\mathrm{Hb}$ 7.0-9.9g/dL) and severe anaemia (haemoglobin $<7 \mathrm{~g} / \mathrm{dL}$ ). However, using this criterion may mean most women would be classified as anaemic in the developing countries including Nigeria. Therefore a pragmatic classification has been used in these settings where the cut off is adjusted downwards to $10 \mathrm{~g} / \mathrm{dl} .{ }^{11}$ The aetiological factors for anaemia in pregnancy vary geographically. The reported principal causes in subSaharan Africa include nutritional deficiencies, malaria, other parasitic infestations and recently, infection with human immunodeficiency virus. Studies have shown that malaria is still a major problem among pregnant women in Nigeria and in other endemic areas. Knowledge of the different causes in a given community is essential for effective control of anaemia. It has been reported that a fall in haemoglobin concentration below $10 \mathrm{~g} / \mathrm{dl}$ cannot be explained by the physiological haemodilution of pregnancy alone, hence its use as a cut off point for diagnosis. $^{14}$

Anaemia has a significant impact on the health of the foetus as well as that of the mother. The deleterious effects of anaemia in pregnancy include increased risk of maternal and foetal morbidity and mortality, preterm delivery, and low birth weight. There is increased risk of maternal, perinatal and infant mortality in pregnant women with severe anemia, an anaemic pregnant woman succumbs easily to obstetric haemorrhage and puerperal infection which are important causes of maternal mortality in developing countries. ${ }^{15}$ Severe anaemia is an important contributor to maternal death through the development of heart failure, particularly around the time of delivery. Prevention of anaemia would therefore help to reduce the high maternal mortality in developing countries including Nigeria. Several studies have been conducted on the prevalence and risk factors of anaemia in pregnancy in different parts of Nigeria.

Northern Nigeria is a socio-culturally distinct region contributing disproportionately to the high national maternal mortality figures. Some of the region's sociocultural practices may be inimical to the haematological status of women during pregnancy and puerperium. For instance, there is a cultural preference for early marriage and high parity especially among women with low educational status. Secondly, girls are discriminated against when it comes to opportunities for western education. Similarly, environmental conditions also favour malarial transmission and hookworm infestation. Furthermore, Low contraceptive uptake and short intervals between pregnancies also deplete maternal iron stores predisposing to maternal anemia in the subsequent pregnancy. On the positive side however, husbands are culturally expected to provide resources for high protein meals during the early puerperium.

In Enugu, Nigeria, the prevalence of anemia in pregnancy among antenatal clinic attendees is persistently high and iron deficiency anemia has been consistently implicated despite the practice of routine iron supplementation in pregnancy. ${ }^{16}$ The major problem with iron supplementation in pregnancy is compliance and this is thought to be a potential driver to the persistent high prevalence of anemia in this population.

Considering the importance of haematinic intake and comparing it with the risk of non-compliance by pregnant women actually triggered this research. The objectives of the study were therefore: to identify types of haematinics and duration of intake during ante natal care, to determine the factors contributing to non-compliance of haematinics and to determine the attitude of pregnant women toward haematinic use. The research hypothesis stipulates that: 1 . There is no significant difference between the age of the pregnant women and factors contributing to noncompliance to routine haematinics, and 2 . There is no significant difference between the educational status of the pregnant women and non-compliance.

\section{METHODS}

\section{Research design}

The research designed is a non-experimental descriptive research used to identify the factors contributing to noncompliance to routine ante-natal haematinics by pregnant woman attending the ante-natal care in the University of Maiduguri Teaching Hospital.

\section{Study setting}

The area of the study the ante-natal care centre (ANC) of University of Maiduguri Teaching Hospital. The ANC is located at the eastern part within the Teaching Hospital; there are five consulting rooms, the offices of the Matron in-charge, the family planning room unit where counselling on the different methods of family planning are carried out, treatment room for collecting specimen for investigation such as High Vaginal Swab (HVS), pap smear and for evacuation. There is a sister's office where observation of vital signs, weight and height are carried out; pregnant women attend the clinics that hold four times in a week. 


\section{Target population}

The target population were the pregnant women attending ANC at University of Maiduguri Teaching Hospital.

\section{Sample and sampling technique}

The sample technique employed was simple random sampling where numbers were given to the pregnant women to choose and the respondents were randomly selected. They were then given the questionnaire to respond to with the aid of an assistant.

\section{Instrument for data collection}

The instrument for data collection was self-developed questionnaires, the questionnaire, comprise of sections A, B, C and D. Section A is the bio-data of respondents, Section B is types of Haematinics, Section C is Factors Responsible for non-compliances to Haematinic and Section D is the information on the important of haematinics.

\section{Statistical analysis}

Data gathered were subjected to SPSS version 20 and analyzed using the same software. Continuous variables were described as mean and standard deviation, whereas, categorical variables were expressed by frequency and percentages.

\section{RESULTS}

Out of the one hundred and thirty questionnaires distributed only one hundred were retrieved given the returning rate at $77 \%$.

Table 1: Frequency of response to the questionnaire based on age of respondents.

\begin{tabular}{|lllll|}
\hline $\begin{array}{l}\text { Age } \\
\text { bracket }\end{array}$ & Frequency & $\begin{array}{l}\text { Percentage } \\
(\%)\end{array}$ & Mean & SD \\
\hline $15-20$ & 11 & 11.0 & & \\
\hline $21-30$ & 62 & 62.0 & & \\
\hline $31-40$ & 22 & 22.0 & & \\
\hline $\begin{array}{l}41 \text { and } \\
\text { above }\end{array}$ & 5 & 5.0 & & \\
\hline Total & 100 & 100.0 & 2.21 & 0.701 \\
\hline
\end{tabular}

Table 1 indicated that the frequency of response to the questionnaire based on age. It shows that the mean and standard deviation. Age falling between 21-30 years had the highest response $62 \%$ followed by $31-40$ years $22 \%$, $15-20$ years $11 \%$ and 41 years and above $5 \%$. The mean of the age response was between 21-30 years, the standard deviation was 0.701 indicating that the observation of the age brackets on the frequency table does not greatly vary from the mean age.
Table 2: Frequency of choice of Haematinics used based on the response from pregnant women.

\begin{tabular}{|lll|}
\hline Haematinic used & Frequency & Percentage (\%) \\
\hline Ferrous Gluconate & 20 & 20.0 \\
\hline Folic Acid & 50 & 50.0 \\
\hline Ranferon & 13 & 13.0 \\
\hline Iron Dextan & 7 & 7.0 \\
\hline Chemiron & 10 & 10.0 \\
\hline Total & 100 & 100.0 \\
\hline
\end{tabular}

Table 2 indicated that the choice of Haematinic used. Ferrous Gluconate had 20\% the acid had 50\%, Ranferon $13 \%$; iron dextan had Chemiron $10 \%$ usage respectively. This shows that respondents accepted the use of Folic acid.

Table 3: Frequency of Trimister of Haematinics intake based on the response from pregnant women.

\begin{tabular}{|lll|}
\hline $\begin{array}{l}\text { Trimester of } \\
\text { Haematinics intake }\end{array}$ & Frequency & Percentage (\%) \\
\hline $1^{\text {st }}$ Trimester & 21 & 21.0 \\
\hline $2^{\text {nd }}$ Trimester & 20 & 20.0 \\
\hline $3^{\text {rd }}$ Trimester & 11 & 11.0 \\
\hline Pregnancy Period & 48 & 48.0 \\
\hline Total & 100 & 100.0 \\
\hline
\end{tabular}

Finding indicates the frequency of response to the questionnaire based on the trimester of Haemtinics intakes. $1^{\text {st }}$ Trimester had $21 \%$ Trimester had $20 \%, 3^{\text {rd }}$ trimester had $11 \%$ and throughout pregnancy period had $48 \%$ of Haematinics intake respectively.

Table 4: Frequency of intake of Haematinics per day based on the response from pregnant women.

\begin{tabular}{|lll|}
\hline Intake per day & Frequency & Percentage (\%) \\
\hline Once & 63 & 63.0 \\
\hline Twice & 24 & 24.0 \\
\hline Thrice & 13 & 13.0 \\
\hline Total & 100 & 100.0 \\
\hline
\end{tabular}

Table 5: Frequency of Haematinics intake by pregnant women based on the different occupational status.

\begin{tabular}{|lll|}
\hline Intake per day & Frequency & Percentage (\%) \\
\hline Civil Servant & 45 & 45.0 \\
\hline Farmer & 2 & 2.0 \\
\hline Business & 24 & 24.0 \\
\hline House Wife & 29 & 29.0 \\
\hline Total & 100 & 100.0 \\
\hline
\end{tabular}

Table 4 indicates the frequency of response to the questionnaire based on the number of times of Haematinics intake per day. Pregnant women taking 
haematinics once a day had $63 \%$ followed by $24 \%$ twice per day and $13 \%$ thrice daily.

Table 5 indicated that civil servants had the highest frequency of about $45 \%$ followed by house wives $(29 \%)$, business class $(24 \%)$ and farmers $(2 \%)$ respectively.

Table 6: Frequency of Haematinics intake by pregnant women based on the different level of education.

\begin{tabular}{|ll|l|}
\hline Level of Education & Frequency & Percentage (\%) \\
\hline Primary & 2 & 2.0 \\
\hline Secondary & 13 & 13.0 \\
\hline House Wife & 29 & 29.0 \\
\hline Islamiya & 9 & 9.0 \\
\hline Tertiary & 70 & 70.0 \\
\hline Quranic & 6 & 6.0 \\
\hline Total & 100 & 100.0 \\
\hline
\end{tabular}

Table 6 indicated the frequency of response to the questionnaire based on the level of education of pregnant women taking haematinics. Pregnant women with tertiary level of education had the highest $(70 \%)$ followed by Secondary (13\%), Islamiya (9\%), Quranic $(6 \%)$ and primary levels $(2 \%)$ respectively.

Table 7: Factors contributing to non-compliance of Haematinics intake based on the response from pregnant women.

\begin{tabular}{|c|c|c|}
\hline Variable & Status & Frequency (\%) \\
\hline \multirow[t]{3}{*}{ Cultural believe } & Yes & 36 \\
\hline & No & 64 \\
\hline & Total & 100 \\
\hline \multirow[t]{3}{*}{ Palatability } & Yes & 59 \\
\hline & No & 41 \\
\hline & Total & 100 \\
\hline \multirow[t]{3}{*}{ Enlightenment } & Yes & 52 \\
\hline & No & 48 \\
\hline & Total & 100 \\
\hline \multirow[t]{3}{*}{ Excessive uptake } & Yes & 54 \\
\hline & No & 46 \\
\hline & Total & 100 \\
\hline \multirow[t]{3}{*}{ Expensive } & Yes & 18 \\
\hline & No & 82 \\
\hline & Total & 100 \\
\hline \multirow[t]{3}{*}{ Smelly } & Yes & 73 \\
\hline & No & 27 \\
\hline & Total & 100 \\
\hline \multirow[t]{3}{*}{ Availability } & Yes & 20 \\
\hline & No & 80 \\
\hline & Total & 100 \\
\hline \multirow[t]{3}{*}{ Vegetable supplement } & Yes & 56 \\
\hline & No & 44 \\
\hline & Total & 100 \\
\hline
\end{tabular}

Table 7 indicates that the frequency of responses to questionnaire based on the factors contributing to noncompliance of Haematinics intake. Those that believed that cultural believes contributed to non-compliance are few with $36 \%$ while $64 \%$ have the opinion that it does not relate to non-compliance. About $59 \%$ are of the opinion that the palatability of the haematinics sequel to non-compliance while $41 \%$ think it doesn't. More than half $52 \%$ agree that enlightenment is associated with the rate of compliance to haematinics while $48 \%$ are of the singular opinion that it does not. Because of the excessive intake nature of the haematinics, $54 \%$ think it causes noncompliance while $46 \%$ do not have that opinion. The cost of the drugs is a phenomenon that $82 \%$ think causes noncompliance while only $18 \%$ think it doesn't. Some haematinics are offensive to the nose for almost $73 \%$ of the respondents while $27 \%$ said it is not related to noncompliance. Twenty percent $20 \%$ think the unavailability of the drugs in Hospitals lead to most cases of noncompliance while the majority $80 \%$ actually don't think it does. The supplementation of Iron by vegetables is a phenomenon that about $56 \%$ think causes noncompliance to haematinics by pregnant women while $44 \%$ are not of the opinion.

Table 8: Information on the importance of Haematinics intake based on the response from pregnant women.

\begin{tabular}{|lll|}
\hline $\begin{array}{l}\text { Ever heard of benefits } \\
\text { of haematinics }(\%)\end{array}$ & Frequency & Percentage \\
\hline Yes & 89 & 89.0 \\
\hline No & 11 & 11.0 \\
\hline Total & 100 & 100.0 \\
\hline Source of information & & \\
\hline Others & 9 & 9.0 \\
\hline Hospital & 60 & 60.0 \\
\hline Pregnant women & 19 & 19.0 \\
\hline Media & 12 & 12.0 \\
\hline Total & 100 & 100.0 \\
\hline Haematinics prevent anemia & \\
\hline Yes & 98 & 98.0 \\
\hline No & 2 & 2.0 \\
\hline Total & 100 & 100.0 \\
\hline Haematinics boosts immunity & \\
\hline Yes & 90 & 90.0 \\
\hline No & 10 & 10.0 \\
\hline Total & 100 & 100.0 \\
\hline
\end{tabular}

Table 8 shows that the frequency of response to questionnaire based on the importance of Haematinics intake. Some pregnant women taking haematinics $11 \%$ never heard about the benefits of the drugs while the majority of others with $89 \%$ take the drugs because they have heard about its benefits. The Hospital was the major source of information $60 \%$ about importance of Haematinics for most pregnant women, other pregnant women $19 \%$ and the media $12 \%$ remain the sources of information for others, $98 \%$ have information that the 
drugs prevents anemia while only $2 \%$ lack such information. The immune boosting ability was a known fact for $90 \%$ of the pregnant women while only $10 \%$ were ignorant of the fact.

Table 9: Hypothesis result (I).

\begin{tabular}{|llll|ll|}
\hline S/N & Age bracket & Mean & SD & DF & P value \\
\hline 1 & $15-20(11)$ & & & & \\
\hline 2 & $21-30(62)$ & & & & \\
\hline 3 & $31-40(22)$ & & & & \\
\hline 4 & $41->(5)$ & 25 & 25.62 & 3 & 0.146 \\
\hline
\end{tabular}

There is no significant relationship between age and noncompliance to haematinics intake in pregnant women.

The results presented in the table indicated that the mean age was $25, \mathrm{Df}=3$ and $\mathrm{P}$ value $=0.146$. Therefore, the $\mathrm{H} 0$ is accepted which states that there is actually no significant difference between the age of pregnant women and non-compliance to haematinics.

This findings is in harmony with reports of Dinga, $(\mathrm{P}=0.6)$ where there is no significant association between age and non-compliance to haematinics intake but it is in contrary with the reports of Bukar and Audu, KNBC and ICF.

There is no significant relationship between educational status and non-compliance to haematinics intake in pregnant women.

Table 10: Hypothesis result (II).

\begin{tabular}{|l|llll|}
\hline S/N & $\begin{array}{l}\text { Educational status } \\
\text { (frequency) }\end{array}$ & Mean & DF & $\begin{array}{l}\text { P } \\
\text { value }\end{array}$ \\
\hline 1 & Primary (2) & & & \\
\hline 2 & Secondary (13) & & & \\
\hline 3 & Islamiyya (9) & & & \\
\hline 4 & Tertiary (70) & & & \\
\hline 5 & Quranic (6) & 20 & 4 & 0.188 \\
\hline
\end{tabular}

The result presented in the table indicates that the mean was $20, \mathrm{Df}=4$ and $\mathrm{P}$ value $=0.188$. Therefore, the $\mathrm{H} 0$ is accepted which states that there is actually no significant difference between the educational status of pregnant women and non-compliance to haematinics.

This findings is in harmony with reports of Dinga, $(\mathrm{P}=0.4)$ where there was no significant association between level of education and non-compliance to haematinics intake.

\section{DISCUSSION}

An overall response rate to factors contributing to noncompliance to routine ante-natal haematinics among pregnant women attending ante-natal clinic in UMTH was $62 \%$, the mean of the age response was between 21-
30 years and the standard deviation was 0.701 indicating that the observation of the age brackets on the frequency table does not greatly vary from the mean age. This is higher than $51.8 \%$ response to effects of non-compliance to haematinics recorded in North Eastern Nigeria. ${ }^{17}$ This difference might be attributed to the difference in sample size and the nature of patients found around the study area as UMTH is now a center harbouring pregnant women from about 27 local governments as a result of the recent insurgency. This high response is not unconnected with the regular enlightenment programs hosted in hospitals and homes on the importance of haematinics within the study area.

The study also show that pregnant women between the ages 21-30years had the highest response $(62 \%)$ followed by $31-40$ years $(22 \%), 15-20$ years $(11 \%)$ and 41years and above $(5 \%)$. The mean of the age response was between 21-35 years, the standard deviation was 0.701 indicating that the observation of the age brackets on the frequency table does not greatly vary from the mean age, this result is in harmony with the findings of Bukar and Audu, where this age bracket recorded a higher response to effects of haematinics in pregnant women. ${ }^{17}$ This might be associated with the fact that women generally between 21-30 years are actually are carried and within the prime reproductive age.

Generally, amongst the choice of haematinics used, Iron dextron had the lowest usage of $7 \%$ while Folic Acid had the highest usage of $50 \%$. Ferrous Gluconate, Ranferon and Chemiron had $20 \%, 13 \%$ and $10 \%$ respectively. The response to the questionnaire based survey indicated that pregnant women taking haematinics for the entire length of the gestation had the highest frequency (48\%) followed by $1^{\text {st }}, 2^{\text {nd }}$ and $3^{\text {rd }}$ trimesters with $21 \%, 20 \%$ and $11 \%$ respectively and only $15 \%$ of women obtain antenatal care in the $1^{\text {st }}$ trimester of pregnancy and the highest which is about $52 \%$ receive haematinics during $3^{\text {rd }}$ trimester of pregnancy. This could be due to the frequent announcement of the importance of haematinics stressed by nursing health workers within the study area as the gestation period progresses. Pregnant women taking haematinics once a day had $63 \%$ followed by $24 \%$ twice per day and $13 \%$ thrice daily. This result is in harmony with previous result where $48 \%$ of the respondent takes haematinics through the length of gestation.

Occupational status of pregnant women taking haematinics had a significant role in the response to haematinics where civil servants had the highest frequency of about $45 \%$ followed by house wives $(29 \%)$, business class $(24 \%)$ and farmers $(2 \%)$ respectively. This is quite contrary to the studies conducted in 2013 where almost $50 \%$ of women basically house wives and farmers don't receive adequate antenatal care and haematinics. ${ }^{18}$ Women in the civil service sector in this survey are more exposed and therefore their high response to haematinic intake is not out of place. 
Educational level plays a vital role in many health related issues. In the present survey pregnant women with tertiary level of education had the highest $(70 \%)$ response followed by Secondary (13\%), Islamiya (9\%), Quranic $(6 \%)$ and primary levels $(2 \%)$ respectively. The result of this survey in entirely different from the reports in where tertiary leveled educated pregnant women had just $18.5 \%$ and those with only secondary leaving certificates had the highest response rate of about $34.5 \% .^{8}$ The difference can actually be attributed to the difference in geographical location and the level of exposure of pregnant women, the fact that many pregnant women having secondary certificate outweigh tertiary levelled educated pregnant women can also be a very reliable reason.

The study area is a composition of many tribes and cultures, those that believe cultural believes contributed to non-compliance are few (36\%) while many $(64 \%)$ have the opinion that it does not relate to noncompliance. About $59 \%$ are of the opinion that the palatability of the haematinics sequel to non-compliance while $41 \%$ think it doesn't , this result is higher than the $47 \%$ palatability reasoning necessitating to noncompliance to haematinic intake reported in, comparable results were found in a study done in Malawi in which $20.7 \%$ of the respondents reported problems with their supplements with $43.6 \%$ of them reporting experiencing nausea. ${ }^{6,8}$ More than half $(52 \%)$ agree that enlightenment is associated with the rate of compliance to haematinics while $48 \%$ are of the singular opinion that it does not, Lynette's report indicated that lack carries $87 \%$ of reason why pregnant women to not adherer to haematinic intake. Because of the excessive intake nature of the haematinics, $54 \%$ of the respondents in this study think it causes non-compliance while $46 \%$ do not have that opinion but the report is contrary in many studies where only $24 \%$ think excessive intake causes the nonadherence to haematinics. ${ }^{8}$ The result of cost of the drugs as a phenomenon in the study area indicated that $82 \%$ are of the opinion that it causes non-compliance while only $18 \%$ think it doesn't, this is completely in contrary to many reports globally where cost of drugs to pregnant women is not as issue at all because of the existing health care programs and facilities particularly for pregnant women and nursing mothers. Some haematinics are offensive to the nose for almost $73 \%$ of the respondents while $27 \%$ said it is not related to non-compliance, many reports are actually having a different opinion where only $2 \%$ think it does. ${ }^{10}$ Twenty percent $(20 \%)$ think the unavailability of the drugs in hospitals lead to most cases of non-compliance while the majority (80\%) actually don't think it does, actually many developing countries have a properly managed program for pregnant women therefore many governmental based hospitals hardly run short of haematinics. The supplementation of Iron by vegetables in this study is a phenomenon that about $56 \%$ think causes non-compliance to haematinics by pregnant women while $44 \%$ are not of the opinion. This high response in vegetable intake agrees with the moving from a monotonous diet to one containing a more diverse range of foods that has been shown to increase intake of energy as well as micronutrients in developing countries, the pregnant women's dietary diversity has been shown to be related to increased nutrient adequacy of the diet. ${ }^{10,19}$

Some pregnant women taking haematinics (11\%) never heard about the benefits of the drugs while a majority of others $(89 \%)$ take the drugs because they have heard about its benefits. This varies with the reports in, where only $37.7 \%$ heard about its benefits before intake. ${ }^{8}$ The Hospital was the major source of information (60\%) about importance of haematinics for most pregnant women, other pregnant women $(19 \%)$ and the media (12\%) remain the sources of information for others, the same study conducted by Lynette reported that $31.9 \%$ got the information from hospital and health related workers, $8.7 \%$ from pregnant women and $11.6 \%$ from the media. Ninety eight percent $(98 \%)$ have information that the drugs prevents anemia while only $2 \%$ lack such information, Lynette report is also in harmony with these values. The immune boosting ability was a known fact for $90 \%$ of the pregnant women while only $10 \%$ were ignorant of the fact. Other reports gathered from the work Lynette, it was indicated that more than half of the pregnant women knew about its immune boosting abilities and only a few never heard about it. ${ }^{8,10}$

\section{CONCLUSION}

In conclusion, the benefits of haematinics are a popular story amongst the pregnant women where the hospital was the major source of their information on how haematinics prevent anemia and boosts immunity during pregnancy. It is therefore recommended that the government should put in place relevant agencies to proactively inform pregnant women cut across all age groups, level of education, occupational classes, cultural inclinations and financial status on the medical importance of haematinic intake during the gestation period.

\section{Funding: No funding sources Conflict of interest: None declared \\ Ethical approval: The study was approved by the Institutional Ethics Committee}

\section{REFERENCES}

1. Afkhami-Ardekani M, Rashidi M. Iron status in women with and without gestational diabetes mellitus. Journal of Diabetes and its Complications. 2009;23(3):194-8.

2. Abdulraheem NM. Protection of women's rights under the nigerian plural legal system: faculty of law, university of ilorin; 2010.

3. Tyndall JA, Okoye V, Elumelu F, Dahiru A, Pariya HB. Vitamin A and iron deficiency in pregnant women, lactating mothers and their infants in Adamawa State, Nigeria: a prospective cohort study. 
American Journal of Food and Nutrition. 2012;2:1420.

4. Villar J, Ba'aqeel H, Piaggio G, Lumbiganon P, Belizán JM, Farnot U. WHO antenatal care randomised trial for the evaluation of a new model of routine antenatal care. The Lancet. 2001;357(9268):1551-64.

5. Osgerby J, Gadd T, Wathes D. The effects of maternal nutrition and body condition on placental and foetal growth in the ewe. Placenta. 2003;24(2):236-47.

6. Kalimbira A, Mtimuni B, Chilima D. Maternal knowledge and practices related to anaemia and iron supplementation in rural Malawi: A cross-sectional study. African Journal of Food, Agriculture, Nutrition and Development. 2009;9(1):550-64.

7. Malek A, Sager R, Eckardt KU, Bauer C, Schneider H. Lack of transport of erythropoietin across the human placenta as studied by an in vitro perfusion system. Pflügers Archiv. 1994;427(1-2):157-61.

8. Dinga LA. Factors associated with adherence to Iron/Folate supplementation among pregnant women attending antenatal clinic at Thika District Hospital in Kiambu County, Kenya: University of Nairobi; 2013.

9. Khan KS, Wojdyla D, Say L, Gülmezoglu AM, Van Look PF. WHO analysis of causes of maternal death: a systematic review. The lancet. 2006;367(9516):1066-74.

10. Jasti S, Siega-Riz AM, Cogswell ME, Hartzema AG, Bentley ME. Pill count adherence to prenatal multivitamin/mineral supplements use among lowincome women. The Journal of nutrition. 2005;135(5):1093-101.

11. Awusi V, Anyanwu E, Okeleke V. Determinants of antenatal care services utilization in Emevor Village, Nigeria. Benin Journal of Postgraduate Medicine. 2009;11(1).

12. Fiedler J, DAgostino A, Sununtnasuk C. A rapid initial assessment of the distribution and consumption of ironâ folic acid tablets through antenatal care in Nepal. 2015.

13. Idowu O, Mafiana $C$, Dopu S. Anaemia in pregnancy: a survey of pregnant women in Abeokuta, Nigeria. African health sciences. 2005;5(4):295-9.

14. Carpenter CJ. A meta-analysis of the effectiveness of health belief model variables in predicting behavior. Health communication. 2010;25(8):661-9.

15. Ezzati M, Lopez AD, Rodgers A, Vander Hoorn S, Murray CJ. Selected major risk factors and global and regional burden of disease. The Lancet. 2002;360(9343):1347-60.

16. Ugwu E, Olibe A, Obi S, Ugwu A. Determinants of compliance to iron supplementation among pregnant women in Enugu, Southeastern Nigeria. Nigerian journal of clinical practice. 2014;17(5):608-12.

17. Bukar M, Audu B, Sadauki H, Elnafaty A, Mairiga A. Prevalence of iron deficiency and megaloblastic anaemia at booking in a secondary health facility in north eastern Nigeria. Nigerian Medical Journal. 2009;50(2):33.

18. Finlayson K, Downe S. Why do women not use antenatal services in low-and middle-income countries? A meta-synthesis of qualitative studies. 2013;10(1):e1001373.

19. Kennedy GL, Pedro MR, Seghieri C, Nantel G, Brouwer I. Dietary diversity score is a useful indicator of micronutrient intake in non-breastfeeding Filipino children. The Journal of nutrition. 2007;137(2):472-7.

Cite this article as: Hambali IU, Kodomi QG, Nelson L, Martins SD, Hambali MU, Kodomi YG, Karagama M. Factors contributing to non-compliance to routine ante-natal haematinics among pregnant women attending ante-natal clinic in University of Maiduguri Teaching Hospital, Borno, Nigeria. Int J Reprod Contracept Obstet Gynecol 2016;5:3824-31. 